\title{
Identifying Fear-evoking Pictures from the International Affective Picture System (IAPS) in a Chilean Sample
}

\author{
Identificando un conjunto de imágenes provocadoras de miedo del International \\ Affective Picture System (IAPS) en una muestra chilena
}

\author{
Carolina P. Moreno \\ Vanetza E. Quezada \\ Andrés Antivilo \\ Departamento de Psicología, Facultad de Ciencias Sociales, Universidad de Chile, Chile
}

Rec. (26 de diciembre de 2015) Acept. (20 de octubre de 2016)

\begin{abstract}
The goal of this study was to identify a valid set of fear-evoking pictures from IAPS images (Lang, Bradley, \& Cuthbert, 2008) in a Chilean Sample. To do so, categorical and dimensional ratings of pictures made by our participants were analyzed, considering potential sex differences. We also evaluated potential transcultural differences by comparing our results with the results of Barke, Stahl, \& Kröner-Herwig (2012), whose methodology was followed in the present study, but incorporating new statistical criteria for the valid identification of pictures that evoke fear. Sixty Chilean volunteers (30 women) with a mean age of 22.3 years rated 146 pictures of the IAPS regarding to the choice of discrete emotions and the ratings of valence, arousal and dominance. Six pictures were identified that evoked fear significantly more than any other emotion. Compared to the German sample, the Chilean group evaluated images with more arousal and valence. Key words: fear, IAPS, categorical evaluations, dimensional evaluations, sex differences.
\end{abstract}

\section{Resumen}

El objetivo del presente estudio fue identificar, en una muestra chilena, un conjunto válido de imágenes provocadoras de miedo a partir de un conjunto de imágenes del IAPS (Lang, Bradley, \& Cuthbert, 2008). Para ello, se analizaron las calificaciones categoriales y dimensionales de las imágenes observadas por 60 participantes, evaluando la existencia de diferencias en función del sexo del examinado. Asimismo, se estudiaron posibles diferencias transculturales, comparando los resultados obtenidos con los hallazgos de Barke, Stahl y Kröner-Herwig (2012), cuya metodología fue similar a la utilizada en este trabajo. Así, 60 voluntarios chilenos (30 mujeres) con una media de 22,3 años, puntuaron 146 imágenes del IAPS respecto a la elección de las emociones y las calificaciones de valencia, excitación y dominio. Se identificaron seis imágenes que provocaron más miedo que cualquier otra emoción. En comparación con la muestra alemana, el grupo chileno evaluó las imágenes con mayor excitación y valencia.

Palabras clave: miedo, IAPS, evaluación caegorial, evaluation dimensional, diferencias por sexo.

\footnotetext{
Correspondence: Should be addressed to Vanetza E. Quezada: ${ }^{2}$ Departamento de Psicología, Facultad de Ciencias Sociales, Universidad de Chile. Av. Ignacio Carrera Pinto \#1045, Ñuñoa, Santiago. qvanetza@u.uchile.cl (+56 2 29787816)/ Escuela de Psicología Pontificia Universidad Católica de Chile (Avda.Vicuña Mackenna 4860, Macul, Santiago).

Acknowledgements: The preparation of this study was partially funded by Conicyt-Chile through an scholarship for doctoral studies in Chile (number 21110311) awarded to Vanetza E. Quezada. The authors are grateful for the cooperation that they received from Isaac Peña-Villalobos and Marcela Díaz during data collection. The authors thank Mario A. Laborda, Gonzalo Miguez and Felipe Alfaro for their comments on an earlier version of this manuscript. The authors declare not having conflicts of interest.
} 


\section{Introduction}

To study emotions, it is fundamental to choose appropriate stimuli to induce specific emotions (e.g., fear) in a controlled way. This is actually an important challenge, considering the deficiencies that researchers report concerning the majority of the multimedia affective databases (e.g., poorly described stimuli that make recovery of semantic information difficult and imprecise; Horvat, Popović, \& Ćosić, 2013). There are currently numerous standardized sets of stimuli to evoke emotions in different modalities (auditory, written and visual) that are freely available to researchers worldwide. The studies that use fear-evoking stimuli usually present them in a visual format (Beckers, Krypotos, Boddez, Effting, \& Kindt, 2013; Bermond, Bierman, Cladder, Moormann, \& Vorst, 2010; Eddy, Mitchell, Beck, Cavanna, \& Rickards, 2011; Eisenberger et al., 2011; Garfinkel, Minati, Gray, Seth, Dolan, \& Critchley, 2014; Golkar, Bellander, Olsson, \& Öhman, 2012; Öhman, Soares, Juth, Lindström, \& Esteves, 2012; Vizueta, Patrick, Jiang, Thomas, \& He, 2012), and among the databases, the International Affective Picture System (IAPS) developed by Lang and colleagues (Lang \& Greenwald, 1988a, 1988b; Lang, Öhman, \& Vaitl, 1988) is the most widely used and contain affective stimuli in the form of natural images (Marchewka, Żurawski, Jednoróg \& Grabowska, 2014).

The IAPS provides a set of normative emotional stimuli for experimental researchers in emotion and attention. It provides a wide set of standardized photographs in color, which evoke positive, neutral and negative affective states and include content in a wide variety of semantic categories (Lang, Bradley, \& Cuthbert, 1997). Studies by the creators of IAPS and by other researchers have shown that it is an instrument that induces reliably emotional, behavioral and physiological responses by means of its pictures, generating an emotional activation similar to what occurs in real situations (Britton, Taylor, Sudheimer, \& Liberzon, 2006; Cuthbert, Bradley, \& Lang, 1996; Lang, Greenwald, Bradley, \& Hamm, 1993; MacNamara, Foti, \& Hajcak, 2009).

The theoretical model of the IAPS is based on three principal dimensions that organize the emotional world at a wide level: valence, arousal and dominance (Silva, 2011). Also, some theoreticians include approach-avoidance in this dimensional model, also known as motivation direction (Davidson, 1999). Valence (or pleasure) and arousal are the strategic dimensions of the emotional world (Bradley \& Lang, 2007). Affective valence refers to the disposition of the organism to situations related to appetitive or aversive motivational features, in a range from very pleasant to very unpleasant. Arousal is the dominant energy or force in the emotional system, and ranges from very calm to very excited. Both valence (or pleasure) and arousal are the strategic dimensions of the emotional world because different values in such dimensions defines different emotions (Bradley \& Lang, 2007; Osgood, Suci, \& Tannenbaum, 1957). Dominance represents the degree of control perceived over the affective stimulus, fluctuating from "in control" to "out of control" (Silva, 2011). Finally, approach-avoidance fluctuates from the tendency to approach the stimuli (e.g., stimuli that generate excitement) and the tendency to avoid them (e.g., stimuli that generate anxiety) (Marchewka et al., 2014; Mauss \& Robinson, 2009).

There is another way to conceptualize emotion that the theoretical model of IAPS does not utilize, the categorical approximation. The categorical approach postulates that the emotional space is composed of a set of discrete and specific affective states that are easily recognizable and mostly distinct from each other, such as fear, anger or happiness (Ekman \& Rosenberg, 1997; Levenson, 1992). From this perspective, six universal affective states have been recognized; anger, disgust, fear, happiness, sadness, and surprise (Ekman \& Friesen, 1975, 1978; Ekman, Friesen, \& Ellasworth, 1972).

In spite of the evident difference that these two theoretical focuses have, Smith and Ellsworth (1985) proposed that they are not incompatible, and that the dimensional model could be useful to describe the similarities and differences between discrete emotions. They are also complimentary if we consider that each discrete emotion represents a combination of dimensions (e.g., fear is a discrete emotion with negative valence, high arousal and a motivational direction of avoidance) (Mauss \& Robinson, 2009).

According to Barke et al. (2012), given that the theoretical origin of the IAPS is based on the dimensional approximation, most research that uses this instrument has been interested in the valence and arousal that the images generate, thus little is known about the discrete emotions that the images evoke. This explains why there are currently only a few studies that provide categorical scores of the images of this instrument (Barke et al., 2012; Davis, Rahman, Smith, \& Burns, 1995; Libkuman, Otani, Kern, Viger, \& Novak, 2007; Mikels et al., 2005). Of these studies, only that of Barke et al. (2012) is specifically focused on fear, and therefore is specially relevant for the present study. The goal of Barke et al. (2012) was to identify a set of images that evoke fear from the pool of the IAPS of Lang, Bradley, and Cuthbert (2008), using categorical and dimensional ratings of a German sample (191 participants, 95 women, mean age 23.6 years). Studying a subset of 298 images selected by six raters (who 
evaluated the complete set of 1182 images), of which 214 images evoked fear and 84 evoked one of other emotional categories (anger, disgust, happiness, sadness, and neutral), 64 fear-evoking pictures were identified. This study also found differences between sexes in the categorical and dimensional scores in an important number of images, as well as dimensional differences compared to the USA norms of the version of the IAPS utilized. The authors concluded that the differences found emphasize the need to use sex-specific and country-specific norms to select affective stimuli.

In Chile, two studies have validated a set of pictures from the IAPS with the dimensional approach (Dufey, Fernández, \& Mayol, 2011; Silva, 2011). The aim of Dufey et al. (2011) was to obtain a valid set of images from the IAPS for a Chilean sample and to compare the results with the norms of the USA of the version of the IAPS utilized (Lang, Bradley $\&$ Cuthbert, 2005). One hundred and thirty five university students evaluated 188 images with dimensions of valence and arousal, using the pencil and paper version of the Self-Assessment Manikin (SAM), an affective evaluation system developed by Bradley and Lang (1994). The internal consistency of the instrument was high for both the valence and the arousal dimension. The results also demonstrated the expected organization of affectivity, with a difference between sexes in the assessment of valence and a difference between countries in the arousal dimension.

The aim of Silva (2011) was to determine the psychometric behavior of the IAPS to assess the instrument and develop norms for the Chilean population. Two hundred and eight university students observed the images of sets 7 and 14 of the original version of the IAPS (Lang, Öhman \& Vaitl, 1988), evaluating the dimensions of valence, arousal, and dominance using the SAM. Both sets showed a psychometric behavior consistent with the existence of segregated motivational systems, with a quadratic association and a boomerang-shaped distribution in the valence/arousal relation. A larger activation gradient was observed for the stimuli classified as negative relative to those classified as positives, along with marginally significant differences between sexes in the activation gradient of pleasant emotions; the gradient was greater in men. Given that these Chilean studies were not designed to evaluate the discrete emotions that the IAPS emotions generate and did not focus specifically on fear, studying the IAPS using a categorical model in a Chilean sample will provide new knowledge to fill up the gap leaved by these two other studies.

Finally, a number of validation studies of the images of IAPS have demonstrated that factors such as sex, culture and sometimes age modify the emotional response that these images generate (Gantiva, Guerra, \& Vila, 2011; Grühn \& Scheibe, 2008; Lasaitis, Ribeiro \& Bueno, 2008; Moltó el al., 1999; Vila et al., 2001; Yi, Liu, Luo, \& Yao, 2006). These results indicate the need to establish specific norms by country, sex and age, in order to choose the visual affective stimuli that are most representative of the reference population, thus contributing to an adequate evaluation and understanding of the emotions in their own cultural context (Moltó et al., 1999).

The goal of this study was to identify, using categorical and dimensional evaluations, a valid set of fear-evoking images in a Chilean sample, using the version of the IAPS of Lang, Bradley, and Cuthbert (2008). Within the categorical dimension of emotions that the IAPS produces, we chose to study fear because its evolutionary significance as an adaptive mechanism, because its importance in clinical research on anxiety disorders, and because of the lack of validated and reliable fear-evoking stimuli to use in experimental situations. The study procedure is based on Barke et al.'s (2012) procedure, but we added new statistical criteria for the identification of images that validly evoke fear. We hope to facilitate future studies on emotions in Chile, especially fear, by providing adequate affective visual stimuli for their studies.

\section{Methods}

\section{Participants}

Sixty Chilean volunteers ( 30 women) of Santiago (Chile) who did not know the specific goals of the research participated in the study. Their mean age was 22.3 years $(\mathrm{SD} \pm$ 3.2). Fifty seven participants reported being enrolled at the university; the other three had only finished high school. All participants were previously evaluated using a preventive medicine checklist in order to exclude individuals with medical or physiological risks.

\section{Stimulus material}

Six raters, using the criteria of Barke et al. (2012), who were also evaluated with the medical checklist, classified a total of 1177 images obtained from the version of the IAPS of Lang, Bradley, and Cuthbert (2008). They evaluated and labeled each image using nine categories (fear, anger, disgust, sadness, happiness, affectionate love, erotic love, surprise, and neutral), plus an additional "other", with a space where they could indicate an emotion other than those in the list 
(see Appendix A). The 70 images that were considered to evoke fear by the majority of the raters were selected for the study. For the eight remaining categories, after eliminating those images evaluated by at least one rater as evoking fear (353), we selected 12 images representing disgust, happiness, sadness, affectionate love, and erotic love, and 3 additional images representing surprise, 1 representing anger, and 12 neutral images. These images were chosen at random among the images that were labeled in each category by the majority of the raters. In contrast to the study of Barke et al. (2012), all the pictures of the IAPS version of Lang et al. (2008) were presented, even those that showed mutilated corpses; this is the reason we made tested participants with the preventive medicine checklist. The final set was composed of a total of 146 images (70 of fear, 12 of disgust, 12 of happiness, 3 of surprise, 1 of anger, 12 of sadness, 12 of affectionate love, 12 of erotic love and 12 neutral)

\section{Procedure}

Before beginning the experiment all participants signed an informed consent form approved by the Ethics Committee of Social Sciences and Humanities of the University of Chile. The parents of the two participants that were less than 18 years old signed an additional consent agreement. The images were evaluated individually using computers in sessions that included from 1 to 25 participants. We used the same procedure as Barke et al. (2012) except for what is detailed below. The presentation of the images of IAPS was performed in computers with a screen of no less than 10 inches, using the E-Prime ${ }^{\circledR}$ software, or where this was not possible, in the portable document format (PDF) of Adobe. For the dimensional evaluations the participants rated valence, arousal and dominance of each image using a 9-point scale (paper and pencil version of SAM; Bradley \& Lang, 1994) (see Appendix B). The process of evaluation of the images lasted approximately 60 minutes, during which each participant gave four evaluations, one categorical and three dimensional, of each image.

\section{Statistical analysis \\ Categorical evaluations}

Using the criterion of simple majority we determined which emotion was associated with each of the images (for the complete sample and separately for men and women), obtaining the frequency of images for each of the categories offered. This was done to compare with the choices previously made by the raters, in which the criterion of simple majority was also used to obtain the set of 146 images. Then to evaluate if the images of fear found are really associated with fear and not another emotion, we used the Chi-square test of the fear category compared to all other choices. By sequential removal of the values of the sum in each image that most contributed to the Chi-square value, we determined for which images the participants chose the category fear in the same proportion as other categories $(p>.05)$ and for which the fear category was significantly greater than the other categories. We complemented this analysis with the values of the Adjusted Standardized Residuals (ASR) for each image of fear obtained by simple majority, testing the significance of fear $v s$. non-fear; these were considered significant $(p<.05)$ when adjusted residuals were $\geq|1.96|$. This analysis was performed both for the complete sample and separately for men and women.

\section{Sex differences}

To determine relations between the categories selected and sex, we used a Chi-square test with the factors sex (woman, man) and category (fear, anger, disgust, sadness, happiness, tender love, erotic love, surprise and other). Then, to determine which specific emotions are associated we first calculated the frequency of emotions that men and women assigned to the total images presented, and then the ASR for each category. Finally, the same analysis was performed for each image separately.

The dimensional evaluations were analyzed using the mean of the scores per image, using Student's t test for independent samples to determine if there were differences between women and men in the evaluations of valence, arousal and dominance. Given that in many cases Levene's test indicated that the assumption of equal variances was not fulfilled, we used Welch's test with equality of variances not assumed. We also used the t-test for independent samples on the total score of each image, to evaluate association between the sex of the participants and their evaluations for each of the dimensions. For the analysis of dimensional evaluation we report the probability $p$ and the size of the effect (Cohen's $d$ ).

\section{Comparison with the study of Barke et al. (2012)}

We compared the fear images found in the Chilean sample with those reported by Barke et al. (2012), using a t-test for independent samples to compare the means of valence and arousal in the two studies, both for the complete sample and separately by sex. We report the probability $p$ and the size of the effect (Cohen's $d$ ) for each analysis of dimensional evaluation. 


\section{Results}

\section{Categorical evaluations}

Forty-three of the 146 images (29.45\%) were labeled as evoking fear by the participants using the criterion of simple majority (The 43 IAPS fear-evoking images are given in Appendix C). This was expectable due to the prior selection of the images that would be included in the study (in which $47.95 \%$ of the total of the categories offered corresponded to the emotion fear). It is important to note that all the fearevoking images found (43) were among the 70 fear images previously chosen for the study.

The Chi-square test found that only one of the 43 images that the participants indicated as fear evoking was chosen as evoking this emotion significantly more than the sum of the other chosen emotions (IAPS image \#1525, called "AttackDog"). Testing men and women separately, women chose only one image as evoking fear significantly more often than they chose other emotions (IAPS image IAPS \#6370, called "MaskedMan"), while in men the test was not significant for any image. Given that finding only one image that evoked fear significantly in the entire sample did not satisfy the goals of the study, we calculated the ASR of the contingency tables for each image in search for significant fear-evoking images. This analysis found six images that evoked significantly more fear than other emotions for the entire sample (which included the two found previously with the Chi-square analysis). For women and men separately were found three and two images, respectively; all were part of the set of six images identified in the complete sample (see Table 1).

Table 1. Fear-evoking images

\begin{tabular}{ccccc}
\hline Image \# & Description & & ASR \\
\hline & & Entire sample & Women & Men \\
\hline 1300 & Pit Bull & 2.2 & & 2.4 \\
1304 & AttackDog & 2.5 & & \\
$1525^{*}$ & AttackDog & 3.5 & 2.6 & 2.4 \\
1932 & Shark & 2.5 & 2.6 & \\
6370 & Masked Man & 2.5 & 3.3 & \\
7640 & Skyscraper & 2.1 & & \\
\hline
\end{tabular}

Note. IAPS image number and descriptions of fear-evoking images found for the entire sample and by sex using Chi-square test and ASR. * Image that evoked significantly more fear.
Sex differences

Differences with the categorical approach

The Chi-square analysis for the association between category chosen and sex of the participants $\left(X^{2}=148.5, p\right.$ $<.001)$ indicated an association between these variables for the total image set. Using ASR and Chi-square by category showed that women labeled a significantly greater number of images with the emotions fear, disgust, sadness and the category other, while mean labeled significantly more images as neutral and surprise than women did. The choice of the emotions happiness, anger, affectionate love and erotic love was independent of sex (for more details see Table 1 of Supplementary Material).

\section{Differences using the dimensional approach}

The $t$-tests for independent samples indicated that women evaluated the images with more arousal than men; they generated a greater sensation of excitation $(t=2.16$ (equal variances not assumed), $p<.05, d=0.54$ ). Significant differences were not found in the evaluations of valence or dominance.

The comparisons of the means of the evaluations of valence, arousal and dominance of each image between men and women found significant differences $(\alpha=.05)$ in 55 images (37.7\%, Cohen's $d=0.51-0.78)$ with respect to at least one of the dimensions, while with respect to the three dimensions together there were only two (1.4\%, Cohen's $d$ $=0.5-0.76)$. Differences in the evaluation of valence were found for 14 images $(9.6 \%$, Cohen's $d=0.5-0.71)$; in the majority of these $(64 \%)$ men evaluated the images more positively than women. In the evaluation of arousal, women and men differed in 40 images (27.4\%, Cohen's $d=0.5-0.78$ ) of the total; women evaluated all these images as evoking more excitation than did men. Finally, in the evaluation of dominance there was a sex difference in 16 images $(11 \%$, Cohen's $d=0.51-0.63$ ); all were evaluated by women as having greater presence of dominance than by men. Table 1 of the supplementary material provides the value of $t, p$ and the size effect (Cohen's $d$ ) for each image.

\section{Comparison with the study of Barke et al. (2012)}

Of the 43 fear-evoking images found in this study, 30 (69.77\%) coincided with those found by Barke et al. (2012). The $t$-tests for independent samples found significant differences between the studies in all the evaluations of valence and arousal, both for the complete sample and for women 
and men separately. The Chilean sample evaluated these 30 fear-evoking images more positively and with greater arousal than their German counterpart; women showed the larger difference in both dimensions (see Table 2).

\section{Discussion}

The main objective of this study was to find a valid set of images of the IAPS (Lang et al., 2008) that evoke fear in a Chilean sample. Of the 146 images evaluated, the participants classified 43 as fear-evoking using the criterion of simple majority. However, using Chi-square and ASR, only six images evoked fear significantly more than any other emotion for the complete sample. Differences in the evaluation of the images were found between sexes and between cultures.

\section{Fear-evoking images}

As in the study of Barke et al. (2012), we conclude that the election of images using the opinion of six raters as the criterion is not an adequate method for the selection of visual stimuli that evoke fear. Even though the participants coincided with the raters in more than half of the images selected there was a difference of $39 \%$, which is an important percentage considering that these images may be used in clinical studies of fear and anxiety disorders. In spite of this, we decided to use this methodology in order to compare with the German study, given that these are the only studies that have tried to establish fear-evoking images using an instrument with affective images. To avoid this problem, the participants could have been asked to evaluate all the images of the IAPS (1177); however, this has practical limitations due to the long time that participants would need to make the four evaluations requested for each image.

Taking this into account, we propose an alternative methodology for the selection of representative images of each category, which consists of evaluating the contrast between the categorical evaluation of the raters and a random selection. Thus, to evaluate if a given image may be assigned to a particular category and be considered representative of the category, we suggest the use of a permutation method (e.g., randomization, jackknife, bootstrap).

In this study, even complementing the Chi-square analysis with the use of ASR we could only identify 6 fear-evoking images out of the 70 included in the study. The low number of images identified as fear evoking may be a consequence of the design of the study and the methodology used (e.g., stimulus material, statistical analyses). The stimulus material used (IAPS) is a factor that probably influenced the small number of fear-provoking images found. Some authors

Table 2. Comparison between german and chilean participants

\begin{tabular}{|c|c|c|c|c|c|c|c|c|c|c|c|c|c|c|}
\hline & \multicolumn{7}{|c|}{ VALENCE } & \multicolumn{7}{|c|}{ AROUSAL } \\
\hline & \multicolumn{2}{|c|}{$\begin{array}{l}\text { Chileans } \\
(\mathrm{n}=60)\end{array}$} & \multicolumn{2}{|c|}{$\begin{array}{c}\text { Germans } \\
(\mathrm{n}=191)\end{array}$} & \multirow[t]{2}{*}{$t^{a}$} & \multirow[t]{2}{*}{$d f$} & \multirow[t]{2}{*}{$\begin{array}{c}\text { Cohen's } \\
d\end{array}$} & \multicolumn{2}{|c|}{$\begin{array}{l}\text { Chileans } \\
(\mathrm{n}=60)\end{array}$} & \multicolumn{2}{|c|}{$\begin{array}{c}\text { Germans } \\
(\mathrm{n}=191) \\
\end{array}$} & \multirow[t]{2}{*}{$t^{a}$} & \multirow[t]{2}{*}{$d f$} & \multirow[t]{2}{*}{$\begin{array}{c}\text { Cohen's } \\
d\end{array}$} \\
\hline & Mean & SD & Mean & SD & & & & Mean & SD & Mean & SD & & & \\
\hline All & 3.83 & 0.4 & 3.17 & 0.7 & $4.68^{* *}$ & 49.3 & 1.09 & 6.2 & 0.4 & 5.62 & 0.6 & a $4.59 * *$ & 51.4 & 1.1 \\
\hline Men & 3.98 & 0.4 & 3.38 & 0.7 & $4.05^{* *}$ & 48.9 & 0.94 & 5.75 & 0.5 & 5.38 & 0.5 & $2.96^{*}$ & 58 & 0.74 \\
\hline Women & 3.68 & 0.5 & 2.95 & 0.6 & $5.15^{* *}$ & 52.3 & 1.22 & 6.64 & 0.4 & 5.88 & 0.6 & a $5.65^{* *}$ & 46.2 & 1.29 \\
\hline
\end{tabular}

Note. Comparison between german and chilean participants in evaluations of valence and arousal for the 30 common fear-evoking images, for the complete samples and separately by sex.

a Equality of variances not assumed

${ }^{*} p \leq .05$

${ }^{* *} p<.01$

1 See Appendix D.

2 The raters were Chilean volunteers with no particular quality other than age within the age range of the participants.

3 For more details see the Stimulus Material section of Barke et al. (2012). 
have criticized the IAPS for the limited number of images it has that belong to a particular category (with a specific content). Along with this, the quality of the IAPS images is not always optimum; some images that belong to a given category have worse quality than those that belong to another semantic category (Delplanque, N'Diaye, Scherer, \& Grandjean, 2007; Marchewka et al., 2014). This is a point to be considered, taking into account that some studies have demonstrated that the physical properties of the images (e.g., size, complexity of the scene, spatial frequency) may influence the affective processing of these visual stimuli (Bradley, Hamby, Löw, \& Lang, 2007; Codispoti, Ferrari, De Cesarei, \& Cardinale, 2006; Wiens, Sand, \& Olofsson, 2011). Thus the poor quality of some of the images presented and their distance from reality may have weakened the capacity of this instrument to evoke emotions (fear in particular) similar to what real situations evoke. It is also possible that the criterion of simple majority employed in the statistical analysis biased the results. This criterion, used to identify the 43 fear-evoking images, showed inconsistency with the analysis of ASR for the images for two reasons. First, the tests of adjusted residuals reduced the number of fear-evoking images from 43 to 6 , which indicates that the images cataloged as fear-evoking using simple majority in reality did not generate this emotion significantly more than the other emotions offered. Second, although according to the criterion of simple majority image \#9930 (ShipWave) evoked fear in the whole population, the ASR showed that this image generated significantly an emotion other than fear $(\mathrm{RTC}=-2.2)$.

\section{Images belonging to other categories}

Of the 70 images selected as fear evoking by the raters, 43 coincided with the evaluation of the participants and 27 were cataloged by the participants as evoking other emotions. These 27 images were labeled (by simple majority) in the categories neutral $(77.78 \%)$, sadness, anger and surprise $(7.41 \%$ each). One possible explanation for the high frequency of the choice of the neutral category is that the contents of a large part of these images are situations of danger distant from the everyday life of the participants (e.g., \#1080,\#1113,\#2690, which show a serpent, a missile and a group of terrorists, respectively). However, the majority of the images that the participants labeled as neutral in this fear-evoking subset were images that do not represent neutral situations (e.g., \#6260, \#6241, \#9440, which show a pointed gun, a revolver and stacked skulls). This might be due to the deficits mentioned above with respect to the physical properties of the IAPS images, to the evaluation context, or to the ambiguous nature of some of these images (Barke et al., 2012; Davis et al., 1995). Although the emotion fear is the focus of this study, it is important to mention what was observed with the rest of the categories offered, considering that there may also be general and sex-specific norms for them. The images that the participants labeled with the emotions disgust, affectionate love and erotic love coincided 100\% with those pre-selected as representative of each emotion. This allows us to conclude that for these emotions, the criterion of selecting images using the evaluation of raters is a trustworthy method to select representative affective stimuli of the sample, also providing another validation of the categorical norms obtained.

\section{Sex differences}

The differences found in the categories chosen by men and women, which were significant for the emotions fear, disgust and sadness for women and for the neutral and surprise categories for men, are consistent with those reported in the literature with respect to sex differences in the evaluation of images from the IAPS belonging to some semantic categories (e.g., aversive images and images with erotic content; Barke et al., 2012; Bradley, Codispoti, Sabatinelli, \& Lang, 2001). These differences were observed mainly in the election of the emotion fear, in which there was a greater propensity in women to judge situations (in this case images) as evoking fear (Barke et al., 2012; Davey, 2008; Gullone, 2000). However, studies similar to ours have not found significant sex differences in the discrete evaluations of images from the IAPS (Davis et al.; 1995; Mikels et al.; 2005). According to Bradley et al. (2001), biological and sociocultural factors may play an important role in sex differences in the modulation of responses to affective stimuli. This would explain why in the rest of the categories evaluated in this study (happiness, anger, affectionate love and erotic love) significant differences between the sexes were not found.

In addition to the above, the differences between sexes found in the evaluation of arousal, in which women evaluated images as evoking significantly more excitation than men, have also been reported in a large part of the validation studies with the dimensional model mentioned in the introduction. All these results reinforce the need to create and utilize specific norms for each sex when affective visual stimuli are used. 


\section{Comparison with the study of Barke et al. (2012) in fear-evoking images}

Of the 64 fear-evoking images found in the study of Barke et al. (2012), 30 coincided with those of the present study (using the simple majority criterion). With respect to the other 34 images, 21 were not part of this study, because the raters did not choose them or because they were not included in the posterior random selection, 9 were labeled by the Chilean sample as neutral, 2 as surprise and 2 as evoking sadness. This, along with the significant difference between sexes found between the studies in all the evaluations of valence and arousal (the Chilean sample evaluated more positively and with more arousal the 30 common images), and the extensive evidence of transcultural differences in the phenomenon of emotion (e.g., Buunk, \& Hupka, 1987; Gantiva, et al., 2011; Mesquita \& Frijda, 1992; Shao-Hua, Ning, \& Wen-Tao, 2005; Terraccinano et al., 2003), emphasize the need to elaborate country-specific norms in the selection of the most appropriate affective visual stimuli for the population studied.

\section{References}

Barke, A., Stahl, J., \& Kröner-Herwig, B. (2012). Identifying a subset of fear-evoking pictures from the IAPS on the basis of dimensional and categorical ratings for a German sample. Journal of Behavior Therapy and Experimental Psychiatry, 43, 565-572. doi: 10.1016/j. jbtep.2011.07.006.

Beckers, T., Krypotos, A. M., Boddez, Y., Effting, M., \& Kindt, M. (2013). What's wrong with fear conditioning? Biological Psychology, 92, 90-96. doi: 10.1016/j.biopsycho.2011.12.015

Bermond, B., Bierman, D. J., Cladder, M. A., Moormann, P. P., \& Vorst, H. (2010). The cognitive and affective alexithymia dimensions in the regulation of sympathetic responses. International Journal of Psychophysiology, 75, 227-233. doi: 10.1016/j.ijpsycho.2009.11.004.

Bradley, M. M., Codispoti, M., Sabatinelli, D., \& Lang, P. J. (2001). Emotion and motivation II: Sex differences in picture processing. Emotion, 1, 300-319. doi: 10.1037/1528-3542.1.3.300

Bradley, M., \& Lang, P. (1994). Measuring emotion: The self-assessment manikin and the semantic differential. Journal of Behavior Therapy and Experimental Psychiatry, 25, 49-59. doi:10.1016/0005-7916(94)900639.

Bradley, M. M. \& Lang, P. J. (2007). The International Affective Picture System (IAPS) in the study of emotion and attention. In J. A. Coan and J. J. B. Allen (Eds.), Handbook of emotion elicitation and assessment (pp. 29-46). Oxford University Press.

Bradley, M. M., Hamby, S., Low, A., \& Lang, P. J. (2007). Brain potentials in perception: Picture complexity and emotional arousal. Psychophysiology, 44, 364-373. Doi: 10.1111/j.1469-8986.2007.00520.x.

Britton, J. C., Taylor, S. F., Sudheimer, K. D., \& Liberzon, I. (2006). Facial expressions and complex IAPS pictures: Common and differential networks. Neuroimage, 31, 906-919. doi: 10.1016/j.neuroimage.2005.12.050

Buunk, B. \& Hupka, R. B. (1987). Cross-cultural differences in the elicitation of sexual jealousy. Journal of Sex Research, 23, 12-22.
Codispoti, M., Ferrari, V., De Cesarei, A., \& Cardinale, R. (2006). Implicit and explicit categorization of natural scenes. Progress in Brain Research, 156, 53-65. doi: 10.1016/S0079-6123(06)56003-0

Cuthbert, B. N., Bradley, M. M., \& Lang, P. J. (1996). Probing picture perception: Activation and emotion. Psychophysiology, 33, 103-111. doi: 10.1111/j.1469-8986.1996.tb02114.x

Davey, G. (2008). Avoidance ratings and fears of Chinese adults by age, ethnic group, sex, and residency. Psychological Reports, 103, 23-34.

Davidson, R. J. (1999). Neuropsychological perspectives on affective styles and their cognitive consequences. In T. Dalgleish \& M. J. Power (Eds.), Handbook of cognition and emotion (pp. 103-123). New York: Wiley.

Davis, W. J., Rahman, M. A., Smith, L. J., \& Burns, A. (1995). Properties of human affect induced by static color slides (IAPS): Dimensional, categorical and electromyographic analysis. Biological Psychology, 41, 229-253. doi:10.1016/ 0301-0511(95)05141-4.

Delplanque, S., N'Diaye, K., Scherer, K., \& Grandjean, D., (2007). Spatial frequencies or emotional effects? A systematic measure of spatial frequencies for IAPS pictures by a discrete wavelet analysis. Journal of Neuroscience Methods, 165, 144-150. doi:10.1016/j.jneumeth.2007.05.030

Dufey, M., Fernández, A., \& Mayol, R. (2011). Adding support to crosscultural emotional assessment: Validation of the International Affective Picture System in a Chilean sample. Universitas Psychologica, 10, 521-533.

Eddy, C. M., Mitchell, I. J., Beck, S. R., Cavanna, A. E., \& Rickards, H. E. (2011). Altered subjective fear responses in Huntington's disease. Parkinsonism \& Related Disorders, 17, 386-389. doi:10.1016/j. parkreldis.2011.01.020

Eisenberger, N. I., Master, S. L., Inagaki, T. K., Taylor, S. E., Shirinyan, D., Lieberman, M. D., \& Naliboff, B. D. (2011). Attachment figures activate a safety signal-related neural region and reduce pain experience. Proceedings of the National Academy of Sciences, 108, 11721-11726. doi:10.1073/pnas.1108239108.

Ekman, P., \& Rosenberg, E. (1997). What the face reveals, basic and applied studies of spontaneous expression using the Facial Action Coding System (FACS). New York: Oxford University Press.

Ekman, P. \& Friesen, W. (1975). Unmasking the face. Englewood Cliffs, NJ: Prentice-Hall.

Ekman, P., \& Friesen,W. V. (1978). Facial Action Coding System (FACS). A technique for the measurement of facial actions. Palo Alto, CA: Consulting Psychologist Press.

Ekman, P., Friesen, W. V., \& Ellasworth, P. C. (1972). Emotions in the human face.

Elmsford, NY: Pergamon.

Garfinkel, S. N., Minati, L., Gray, M. A., Seth, A. K., Dolan, R. J., \& Critchley, H. D. (2014). Fear from the heart: Sensitivity to fear stimuli depends on individual heartbeats. The Journal of Neuroscience, 34, 6573-6582. doi: 10.1523/JNEUROSCI.3507-13.2014

Gantiva, C., Guerra, P., \& Vila, J. (2011). Validación colombiana del sistema internacional de imágenes afectivas: Evidencias del origen transcultural de la emoción. Acta Colombiana de Psicología, 14, 103-111.

Golkar, A., Bellander, M., Olsson, A., \& Öhman, A. (2012). Are fear memories erasable? Reconsolidation of learned fear with fear-relevant and fear-irrelevant stimuli. Frontiers in Behavioral Neuroscience, 6, 1-10. doi: 10.3389/fnbeh.2012.00080

Grühn, D., \& Scheibe, S. (2008). Age-related differences in valence and arousal ratings of pictures from the International Affective Picture System (IAPS): Do ratings become more extreme with age? Behavioral Research Methods, 40, 512-521. doi: 10.3758/BRM.40.2.512

Gullone, E. (2000). The development of normal fear: A century of research. Clinical Psychology Review, 20, 429-451. doi: 10.1016/ S0272-7358(99)00034-3

Horvat, M., Popović, S., \& Ćosić, K. (2013). Multimedia stimuli databases usage patterns: A survey report. In Proceedings of the $35^{\text {th }}$ International ICT Convention MIPRO 2013, 1265-1269.

Ito, T. A., Cacioppo, J. T., \& Lang, P. J. (1998). Eliciting affect using the International Affective Picture System: Trajectories through evaluative space. Personality and Social Psychology Bulletin, 24, 855-879. 
Kirouac, G., \& Dore, F. Y. (1985). Accuracy of the judgment of facial expression of emotions as a function of sex and level of education. Journal of Nonverbal Behavior, 9, 3-7. doi:10.1007/BF00987555

Lasaitis, C., Ribeiro, R., \& Bueno, O. (2008). Brazilian norms for the International Affective Picture System (IAPS). Comparison of the affective ratings for new stimuli between Brazilian and North-American participants. Revista Brasileira de Psiquiatria, 57, 270-275.

Lang, P. J., \& Greenwald, M. K. (1988a). The International Affective Picture System standardization procedure and initial group results for affective judgments. (Tech. Rep. IA). Gainesville, FL: The Center for Research in Psychophysiology, University of Florida.

Lang, P. J., \& Greenwald, M. K. (1988b). The International Affective Picture System standardization procedure and initial group results for affective judgments. (Tech. Rep. IB). Gainesville, FL: The Center for Research in Psychophysiology, University of Florida.

Lang, P. J., Öhman, A. \& Vaitl, D. (1988). The International Affective Picture System [Photographic slides]. Gainesville, FL: The Center for Research in Psychophysiology, University of Florida.

Lang, P. J., Greenwald, M. K., Bradley, M. M., \& Hamm, A. O. (1993). Looking at pictures: Affective, facial, visceral, and behavioral reactions. Psychophysiology, 30, 261-273. doi: 10.1111/j.1469-8986.1993. tb03352.x.

Lang, P. J., Bradley, M. M., \& Cuthbert, B. N. (1997). International Affective Picture System (IAPS): Technical manual and affective ratings. (Tech. Rep. A-6). Gainesville, FL: University of Florida, NIMH Center for the Study of Emotion and Attention.

Lang, P. J., Bradley, M. M., \& Cuthbert, B. N. (1999). International Affective Picture System (IAPS): Technical manual and affective ratings. University of Alabama-Birmingham, NIMH Center for the Study of Emotion and Attention.

Lang, P. J., Bradley, M. M., \& Cuthbert, B. N. (2005). International Affective Picture System (IAPS): Affective ratings of pictures and instruction manual. (Tech. Rep. A-6). Gainesville, FL: University of Florida.

Lang, P. J., Bradley, M. M., \& Cuthbert, B. N. (2008). International Affective Picture System (IAPS): Affective ratings of pictures and instruction manual (Tech. Rep. A-8). Gainesville: University of Florida.

Levenson, R. (1992). Autonomic nervous system differences among emotions. Psychological Science, 3, 23-27.

Libkuman, T. M., Otani, H., Kern, R., Viger, S. G., \& Novak, N. (2007). Multidimensional normative ratings for the International Affective Picture System. Behavior Research Methods, 39, 326-334. doi:10. 3758/s13428-013-0379-1

MacNamara, A., Foti, D., \& Hajcak, G. (2009). Tell me about it: Neural activity elicited by emotional pictures and preceding descriptions. Emotion, 9, 531-543. doi:10.1037/a001625

Marchewka A., Żurawski Ł., Jednoróg K., \& Grabowska A. (2014). The Nencki Affective Picture System (NAPS): Introduction to a novel standardized wide range high quality realistic pictures database. Behavior Research Methods, 46, 596-610. doi: 10.3758/s13428-013-0379-1.

Mauss, I. B., \& Robinson, M. D. (2009). Measures of emotion: A review. Cognition and Emotion, 23, 209-237. doi: 10.1080/02699930802204677

Mesquita, B. \& Frijda, N. (1992). Cultural variations in emotions: A review. Psychological Bulletin, 112, 179-204. doi: 10.1037/00332909.112.2.179

Mikels, J. A., Fredrickson, B. L., Larkin, G. R., Lindberg, C. M., Maglio, S. J., \& Reuter-Lorenz, P. A. (2005). Emotional category data on images from the International Affective Picture System. Behavior Research Methods, 37, 626-630.

Moltó, J., Montañés, S., Poy, R., Segarra, P., Pastor, M., ... Vila, J. (1999). Un nuevo método para el estudio experimental de las emociones: el International Affective Picture System (IAPS). Adaptación española. Revista de Psicología General y Aplicada, 52, 55-87.

Öhman, A. (2008). Fear and anxiety. In M. Lewis, J. Haviland-Jones, \& L. Feldman (Eds.), Handbook of emotions (709-729). New York: The Guilford Press.

Öhman, A., Soares, S. C., Juth, P., Lindström, B., \& Esteves, F. (2012). Evolutionary derived modulations of attention to two common fear stimuli: Serpents and hostile humans. Journal of Cognitive Psychology, 24, 17-32. doi: 10.1080/20445911.2011.629603

Osgood, C. E., Suci, G., \& Tannenbaum, P. (1957). The measurement of meaning. Urbana, IL: University of Illinois Press.

Sabadías, A. V. (1996). Estadística descriptiva e inferencial (2da ed.). Murcia, España: Universidad de Castilla-La Mancha.

Shao-Hua, H., Ning, W., \& Wen-Tao, G. (2005). Cross-cultural study of affective reactions of Chinese and American healthy adults. Chinese Journal of Clinical Psychology, 13, 265-266.

Silva, J. (2011). International Affective Picture System (IAPS) in Chile: A cross-cultural adaptation and validation study. Terapia Psicológica, 29, 251-258. doi: 10.4067/S0718-48082011000200012

Smith, C. A., \& Ellsworth, P. C. (1985). Patterns of cognitive appraisal in emotion. Journal of Personality and Social Psychology, 48, 813-838. doi: $10.1037 / 0022-3514.48 .4 .813$

Terracciano, A., Merritt, M., Zonderman, A. B., \& Evans, M. K. (2003). Personality traits and sex differences in emotion recognition among African Americans and Caucasians. Annals of the New York Academy of Sciences, 1000, 309-312.

Vila, J., Sánchez, M., Ramírez, I., Fernández, C., Cobos P.,...Moltó, J. (2001). El Sistema Internacional de Imágenes Afectivas (IAPS): Adaptación española. Segunda Parte. Revista de Psicología General y Aplicada, 54, 635-657.

Vizueta, N., Patrick, C. J., Jiang, Y., Thomas, K. M., \& He, S. (2012). Dispositional fear, negative affectivity, and neuroimaging response to visually suppressed emotional faces. Neuroimage, 59, 761-771. doi: 10.1016/j.neuroimage.2011.07.015

Wiens, S., Sand, A., \& Olofsson, J. K. (2011). Nonemotional features suppress early and enhance late emotional electrocortical responses to negative pictures. Biological Psychology, 86, 83-89. doi: 10.1016/j. biopsycho.2010.11.001

Yi, J.-Y., Liu, M.-F., Luo, Y.-Z., \& Yao, S.-Q. (2006). Sex differences in the reaction to emotional pictures. Chinese Journal of Clinical Psychology, 14, 583-585. 
